\title{
O desafio entre teoria e prática na formação de professores
}

MOHR, Adriana; WIELEWCKI, Hamilton de G. (Orgs.).

Prática como componente curricular: que novidade é essa 15 anos depois? 1. ed. Florianópolis: NUP/CED/UFSC, 2017, 272 pp.

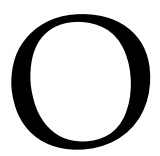

livro oferece um conjunto de textos dedicados a tema muito próximo de um problema central da educação brasileira, a formação de professores da educação básica. A centralidade da educação para o desenvolvimento do país é há muito reconhecida, a partir de todas as perspectivas sociais e o papel do professor e da sua formação ganha vulto crescente, a despeito da grande evolução tecnológica em torno do trabalho educativo. Não é o caso de trazer discussões que justapõem professores e recursos tecnológicos e deixam claro a permanência do lugar do professor na educação de crianças e jovens. Não posso, entretanto, me furtar à observação de uma lição muito importante no momento crítico que vivemos, em meio à pandemia (2020), ao sermos obrigados a lançar mão da educação a distância, já que o encontro presencial nas escolas teve que ser suspenso. O esforço feito por professores, pais e estudantes da educação básica tem sido imenso, mas a realidade vivida por todos eles e exibida com frequência pela mídia, em especial pela TV, deixa claro o quanto sentem, todos eles, por estar distantes do trabalho educativo a que estavam habituados em suas escolas, a despeito das limitações. Professores, alunos e também os pais estão muito pouco preparados para enfrentar o desafio imposto pela pandemia e a própria tecnologia disponível (e em parte, ao menos, já utilizada há bastante tempo) ainda se encontra bem aquém do necessário desempenho esperado. Não é o caso de aprofundarmos aqui o pensamento a esse respeito, o que, por certo, deverá ser feito por estudiosos do tema, estimulados pela imperiosa exigência que estamos vivendo.

Dentro do quadro da formação de professores para a educação básica destaca-se, como bem ressaltado pelos estudiosos do tema, a perene questão da relação entre teoria e prática. Ejunto a ela aparece também com destaque a figura do estágio supervisionado, que ganhou estatuto de lei há pouco mais de 50 anos, em 1969, pelo Decreto-Lei no 1044. Passado todo esse tempo, essa figura obrigatória por lei na composição do curso de formação inicial de professores, a licenciatura, ainda não tem uma realização plenamente satisfatória, correspondente à importância do lugar a ela atribuído legalmente. Assinalo essa defasagem entre leis e realidade, bastante frequente no campo educacional, porque 
constitui um objeto presente em muitas investigações, marcando por isso um dos eixos da minha abordagem neste texto. Ao lado de outro eixo, representado pelo papel da pesquisa na formação e no trabalho do professor, compõem minha expectativa na leitura do livro e na proposta para esta resenha.

O livro foi publicado em 2017, com estudos desenvolvidos pelos autores, professores qualificados, com formação em mestrados, doutorados e experiência de docência em universidades públicas, em sua maioria, alguns tendo participado de trabalhos ligados à implementação da nova disciplina Prática como componente curricular (PCC), foco central na elaboração do livro. A disciplina foi instituída pelas resoluções CNE/CP 1/2002 e 2/2002 do Conselho Nacional de Educação (CNE), para que todos os professores envolvidos com os cursos de licenciatura passassem a integrá-la em seus currículos, o que foi reafirmado na mais recente Resolução do CNE/CP nº 2, de 1ํㅡㄹ de julho de 2015, definindo Diretrizes Curriculares Nacionais para a formação inicial em nível superior. Há, portanto, um largo período de vigência da proposta legal da disciplina entre os cursos de licenciatura, o que levou os autores, estimulados pela diretriz de 2015 a voltar sua atenção às experiências ligadas a sua implementação, como insinua a simpática ironia do subtítulo do livro: "que novidade é essa 15 anos depois?". Os organizadores, na apresentação do livro, acentuam a importância da atenção e do trabalho investigativo dedicados à situação em que se encontrava a disciplina, na época, depois de um considerável tempo de vivência. E insistem que é fundamental entender bem o seu significado, antes de pensar em reforma-la (p.6). Para tanto, propõem o livro organizado em três partes, procurando responder a questões que ressaltam a posição da prática docente como "um fundamento básico da concepção e organização dos currículos das licenciaturas". Assumem que a concentração dos estudos apresentados sobre cursos de ciências biológicas não compromete o escopo central do livro, o que parece bastante razoável, ainda que traga sinais claros da área específica.

A Parte Ié consagrada a esclarecer o que é a prática como componente curricular, em dois capítulos, que se complementam. No primeiro, Origem e contornos da PCC, B. Pereira e A. Mohr acompanham a origem e o desenvolvimento da concepção da PCC, ao longo dos 15 anos, desde sua proposta original. Apresentam e discutem os muitos problemas enfrentados pela formação de professores no período, destacando sempre a importância da prática para essa formação. São apontados e analisados resoluções e pareceres emanados do CNE, que introduzem e procuram esclarecer a proposta da nova disciplina, com destaque para o Parecer CNE/CES nํ15, de fevereiro de 2005, que procura responder dúvidas sobre a sua implementação. A PCC supõe atividades sob a supervisão de professores da universidade e também "da escola, onde o estudante experimenta situações reais de exercício profissional" (p. 32). Ficam abertas às instituições formadoras iniciativas para a dedicação das 400 horas da PCC, às mais variadas atividades que possam acompanhar os estudantes em seu curso, desde o início, procurando "articular dimensões teóricas e 
práticas, os conhecimentos a serem ensinados e os conhecimentos da ação pedagógica", sem deixar de considerar sua contribuição para a transposição didática (p. 33). Fica claro, como ressaltam os documentos, que a "PCC não é o estágio supervisionado, o qual requer inserção na sala de aula e acompanhamento de um profissional da educação básica". As 400 horas introduzidas pela PCC devem ser distribuídas ao longo do curso de licenciatura "com o objetivo principal de não deixar apenas para o estágio supervisionado o papel de preparação para a prática docente" (p. 33). Essas horas devem ser dedicadas a atividades práticas de diferentes tipos e meios, como livros, filmes, depoimentos e outras mídias, sem "necessariamente o contato direto e in loco na escola". Essas atividades e as reflexões despertadas a partir delas podem contribuir para esclarecer um ponto que tem sido objeto de dúvidas, segundo as autoras, e se origina na aproximação "errônea" entre a prática e a "necessidade de estar na escola e interagir diretamente com os alunos" e "colocar a mão na massa" (p. 35). A noção de prática, na legislação analisada se refere à ação ou trabalho docente e pedagógico, não acontece ou se esgota apenas no contato com os alunos ou no dar aulas. Ela vai muito além, não se confundindo, porém, com a prática desenvolvida nos laboratórios próprios da área focalizada, ciências biológicas. Há neste primeiro capítulo um esforço claro das autoras de procurar esclarecer o sentido da proposta legislativa, em suas várias manifestações, em direção à noção de prática, introduzida pela nova disciplina, PCC, como bem mais ampla do que a comumente atribuída ao trabalho do estágio supervisionado, em geral atrelado ao final do curso de licenciatura, com o encargo de oferecer ao estudante em formação a carga exigida de "prática na realidade escolar". Este aspecto não chega, porém, a ser discutido no texto.

No segundo capítulo da Parte I, um grupo de autores (Ferreira, Souza, Fonseca, Etter e Santos) trabalha com o desafio de ver de perto Reformas curriculares do/no tempo presente. Enquanto no primeiro capítulo a empreitada era tratar da concepção da proposta da nova disciplina, a PCC, neste segundo tratou-se de examinar experiências vividas por ela nos currículos de cursos de licenciatura em ciências biológicas, em três universidades públicas de reconhecida maturidade: UFRRJ, UFMG e UERJ. O grupo estava envolvido em dois projetos de pesquisa, com foco sobre a relação entre teoria e prática na formação de professores, com interesse especial sobre histórias e políticas de currículo. No texto estão analisadas contribuições importantes de autores dedicados ao estudo das questões, como Ball, Ricoeur, Popkevitz, consultados em suas publicações, e também pelas análises de estudiosos dos temas entre nós, como Carmen Gabriel e Jefferson Mainardes, o que acrescenta um valor especial às discussões, à luz de nossos problemas específicos. $\mathrm{O}$ trabalho diretamente com Popkevitz foi beneficiado por um período como Visiting Schollar de uma das pesquisadoras do grupo, M. S. Ferreira, junto à Universidade de UW-Madison.

Embora partindo de estudos na área específica das ciências biológicas, os autores assinalam a permanência de tradições bem estabelecidas em nossa história da formação de professores, em tempos e instituições diferentes, com as quais os conhecimentos 
da área específica dialogam, como constatam nas três universidades investigadas, com repercussões sobre características dos currículos oferecidos em seus cursos (p. 49) Com apoio na discussão teórica, procuram verificar como a inovação representada pela PCC negocia com as referidas tradições, entendidas como regularidades discursivas, em um jogo onde "inovação e tradição não são percebidas em polos opostos", mas em um contínuo construtivo do currículo (p. 52). O capítulo traz contribuições importantes, pelas pesquisas relatadas e as que pode sugerir.

A segunda parte do livro se dedica a analisar possibilidades curriculares para a PCC, em seus quatro capítulos. No primeiro, o terceiro do livro, Mohr e Cassiani, ampliam e trazem lições apresentadas em artigo anterior, a partir de experiências desenvolvidas na UFSC desde 2006. Começando com a acolhida ao curso de licenciatura pelo departamento de ciências biológicas, reconhecendo o interesse da preparação do educador, não apenas para o futuro professor de biologia, mas para o próprio biólogo, formado pelo bacharelado, em sua futura profissão. A valorização da preparação pedagógica ou didática, dois termos de difícil manuseio por profissionais de áreas distintas da educação, mostra-se logo pelo acréscimo da letra $\mathrm{P}$ ao título da nova disciplina, Prática Pedagógica como Componente Curricular (PPCC). E o relato das experiências pelas autoras mostra o empenho com que foram conduzidas, estimulando o aprofundamento de análises sobre pontos problemáticos, há muito pendentes como desafios à formação de professores. Entre eles ressalta-se a concepção de prática, em um grupo de formadores de composição heterogenea voltados em conjunto para esses desafios, em excelente ocasião para exposição e discussão de ideias, por vezes bem divergentes, em esforço comum, no qual os participantes se reconhecem vivendo um processo de crescimento profissional. Há vários outros pontos que merecem explorações analíticas, a serem aproveitadas a partir de uma pesquisa estimulante.

No segundo capítulo da segunda parte, $4^{\mathrm{0}}$ do livro Por entre as palmas deste lugar..., dois autores, Oliveira e Brito, trazem análises sobre duas experiências com a implantação da PCC, em duas universidades estaduais, a Uece e a Uesc de Santa Cruz na Bahia, nas quais foram adotadas articulações diferentes para a organização curricular. Pela Uece, a distribuição da nova disciplina foi para um número grande de disciplinas específicas da área, e pela Uesc para um conjunto de oito módulos, em ambas as instituições acompanhando o curso de licenciatura desde o seu início. A variedade de disciplinas na Uece procurando atender à necessidade de preparação específica na área aos futuros professores, já que os docentes atuais do curso de licenciatura não apresentavam essa formação. Isso poderia ser coberto pela interação com colegas da área específica envolvidos no curso. Uma série de atividades foram propostas, para que os estudantes pudessem reunir teoria e prática em sua formação, tais como: análises críticas de livros didáticos, pesquisa de material didático alternativo, elaboração de textos didáticos, produção de material didático além de textos e elaboração de projetos investigativos ligados a temas 
ambientais. Além de atividades em conjunto, como seminários, painéis, oficinas, palestras, entre outras, "como se estivessem em salas de aula, que poderiam ser realizadas na educação básica" (p. 96). São, portanto, atividades realizadas no âmbito da universidade, entre estudantes e professores em suas aulas, procurando representar o ambiente de trabalho das escolas de educação básica, em um tipo de prática bastante frequente em cursos de licenciatura, que está carecendo de uma análise atenta a seus aspectos positivos e negativos. Na UESC a nova disciplina se distribuiu entre oito módulos voltados para o conhecimento do contexto no qual se situam as escolas visadas, inclusive por meio de projetos dos próprios estudantes, propostos a partir do contato com as escolas pelo estágio. São dois caminhos procurando explorar soluções e possibilidades curriculares para a entrada da PCC em cursos de licenciatura, ambos buscando a integração entre teoria e prática na formação de futuros professores, pelo trabalho com os conhecimentos e saberes dos diferentes campos disciplinares e a consideração do contexto da educação básica. Fica assinalada pelos autores a cautela em relação às vivências oferecidas por atividades no curso que precisam dialogar com a realidade escolar e seu contexto, sob o risco de ceder "a um imaginário que idealiza escolas" (p. 101). Alertam também para o perigo de achar que o "simples contato com a realidade é o suficiente para compreendê-la e nela atuar" (p. 102).

Há uma questão de fundo, ligada às duas composições curriculares propostas e a muitas outras experimentadas em nossas IES, provavelmente a atribuição ao estágio supervisionado da função de introdução do estudante do curso de licenciatura à prática docente. A discussão, importante e necessária, sobre a concepção de prática em sua relação com a teoria nos cursos de formação de professores, acaba sofrendo um colapso ao se entregar ao estágio a responsabilidade pelo contato com a "realidade do magistério", ou da docência, de modo efetivo. Sobretudo se atentarmos para as atuais condições nas quais o estágio é realizado. Ele continua, entretanto, como exigência legal do curso, ocupando uma disciplina específica, com seu número de horas e várias outras exigências devendo ser cumpridas, incluindo uma parte, obrigatória também, que cabe ao professor da escola básica, que recebe o estagiário em sua sala de aula e deve supervisionar e avaliar seu trabalho acadêmico. Sem ser preparado, equipado, acompanhado, compensado ou mesmo consultado para isso. Este é um grande problema que extrapola os limites deste trabalho, mas precisa ser lembrado, porque pode comprometer o esforço de professores e coordenadores na organização do curso com a nova disciplina.

O quinto capítulo focaliza a criação e desenvolvimento de um novo curso de licenciatura na Ufscar, em seu campus de Sorocaba, dentro da perspectiva da Parte II do livro, tratando de soluções e possibilidades com a PCC. O curso começa a atuar em 2006, sendo em 2009 desdobrado para atender alunos no período noturno. A autora, Torres, deixa clara sua visão crítica à situação dos cursos de formação de professores dominante até perto do final do século XX e sua expectativa de que a nova legislação possa abrir caminho para 
a busca de condições para a esperada integração ente formação teórica e prática, tarefa para toda a equipe de formadores e não, apenas, para o supervisor do estágio. As 400 horas da PCC "objetivam superar a ideia de que o estágio é o espaço reservado à prática, enquanto na sala de aula se dá conta da teoria" (p. 109). Com esta perspectiva é desenvolvido o estudo, baseando-se em documentos legais e nos preparados por equipes da universidade para a composição curricular do novo curso, aos quais foram acrescentados depoimentos obtidos em conversas com os professores. $\mathrm{O}$ relato mostra uma variedade de disciplinas experimentando possibilidades a partir das novas horas oferecidas pela PCC, entre elas duas dirigidas à orientação de Estágio Supervisionado em Biologia e duas à orientação de Estágio Supervisionado em Ciências, sendo também considerada como disciplina com carga horária da PCC a monografia. São inovações curriculares cujo andamento gostaríamos muito de conhecer, por se relacionarem com o estágio, exigência legal do curso, mas contando com poucos recursos e condições para sua realização satisfatória. A composição das disciplinas novas indica inclinação do tratamento do lado pedagógico das questões mais a cargo dos docentes do campo específico da educação, que, por sua vez, não demonstram domínio suficiente para assegurar a formação dos futuros professores na área da biologia. Situação comum nos cursos de licenciatura, o que leva a autora a acentuar a necessidade de formação dos docentes, sobretudo os da área específica. Ela acena para a importância de se unirem, o corpo docente e o discente, em uma comunidade acadêmica, trabalhando na construção e reconstrução crítica e participativa da matriz curricular. Não menciona, entretanto, a integração dos professores da escola básica nesse esforço, condição indispensável para o trabalho efetivo que cabe ao estágio. Termina trazendo um grupo ainda ausente do relato, os licenciandos, em uma "pesquisa que poderia contribuir para uma melhor compreensão desse panorama" (p. 119). O conjunto de disciplinas e estratégias ensaiadas pelos atores do novo curso, para introdução da PCC, constitui excelente cenário para pesquisas, como possibilidades de soluções curriculares para os cursos de licenciatura.

O 6o capítulo, fechando a segunda parte do livro, oferece Soluções e Possibilidades Curriculares para a PCC. Retoma um capítulo da tese defendida por um dos autores, Wielewicki, em 2010, que o elabora em parceria com sua orientadora, Krahe. Contam, assim, com sólido ponto de partida para discutir desafios enfrentados na organização curricular de cursos de licenciatura com a integração da PCC, em sua própria instituição, a UFRGS e na vizinha UFSM. Com base em dados e análises atualizados, os autores desenvolvem a discussão em torno da PCC, desvelando aspectos só perceptíveis por meio de pesquisa que se aproxime dos sujeitos envolvidos. Destacam-se, assim, depoimentos de professores e coordenadores, infelizmente não sendo consultados licenciandos e seus supervisores nas escolas. Pode-se perceber, pela voz dos professores da universidade, a dificuldade da integração entre eles e os que trabalham, como eles, na formação dos licenciandos, recebidos em suas escolas, sobretudo, embora não apenas, durante o estágio. 
Lembram os autores que uma das intenções da proposta original da PCC era evitar que a prática docente fosse deixada por conta do estágio, como vinha sendo. Entretanto, a compreensão e o esforço do pessoal da universidade pela indispensável integração não têm conseguido ultrapassar obstáculos que dificultam a construção da esperada ponte entre as duas instituições. Há limites em ambos os lados, mas os da escola são de natureza estrutural, bem mais difíceis de enfrentar, como as condições de trabalho, de modo especial quanto ao tempo do seu professor. A questão do tempo é lembrada, entre outros pontos no texto, em relação à duração do estágio, insuficiente para assegurar ao estagiário uma prática docente mais próxima à realidade escolar, além das simples observações da escola e das aulas do professor supervisor (p. 133,4).

São vários os aspectos apontados pelos autores que merecem consideração, de leitores interessados como eles em esclarecer a ajuda da PCC para o curso de formação de professores, tendo sempre em mente o equilíbrio ente teoria e prática. Entre esses aspectos destaca-se a atenção ao estágio supervisionado, já assinalado, no centro de "um arranjo mais orgânico entre universidade e escola, entre formação e profissão" (p. 127). Também a prática reafirmada pela PCC, recebe atenção especial, pelas diferentes organizações que, nas duas instituições investigadas, procuram um lugar certo para integrá-la no curso de formação de professores. O trabalho com professores de uma área específica propicia o tratamento de questões há muito esperando por aprofundamento. Entre as quais o modo de perceber e de trabalhar com a prática, bem distinto entre os professores das duas áreas, todos empenhados em desenvolver o melhor trabalho possível, com vistas à aprendizagem dos alunos, cada grupo vindo de seu território próprio. O pessoal das ciências biológicas com a sabedoria da prática de laboratório, via segura de acesso ao conhecimento para os estudantes e o pessoal da pedagogia - já que na educação estão todos - com seu capital teórico e didático construído na área, os dois grupos vivendo excelente oportunidade de trabalhar em conjunto no confronto entre os dois domínios, na experiência centrada na introdução da PCC.

Abrindo a parte III do livro sobre A PCC na visão de professores e estudantes, temos no capítulo 7 mais uma tese de 2014 dando base ao artigo de Silvério, L.E.R, tratando dos desafios e possibilidades para a integração entre formação acadêmica e campo profissional da docência. A pergunta inicial proposta pelo autor o acompanha ao longo de todo o texto, focalizando a integração entre a PCC e o estágio, preocupação frequente em estudos sobre o tema, inclusive entre os reunidos nesta obra. Essa relação acaba comprometendo o alcance da nova disciplina pela reconhecida insuficiência de recursos e condições para o efetivo trabalho do estágio. No texto são apresentadas constatações da pesquisa do autor, como professor em cursos de licenciatura em ciências biológicas na UFSC, em trabalho com mais de 100 estudantes desses cursos (não fica claro se por meio de questionários, entrevistas ou outro tipo de instrumento) e pelo acompanhamento de dois desses estudantes já na fase final do curso. Os resultados não são muito animadores 
para o autor, ao revelar no grupo numeroso de estudantes uma visão da nova disciplina a serviço de uma aprendizagem mais eficiente do conteúdo específico do curso, pela elaboração de materiais e estratégias de ensino, tanto no decorrer das disciplinas das várias áreas, quanto no próprio estágio nas escolas. Os estudantes consultados chegam a afirmar que os professores de licenciatura deveriam cuidar de uma preparação melhor dos futuros professores e talvez até um manual poderia ser elaborado para orientar o trabalho dos professores. O que o autor comenta como "uma visão superficial da realidade e da cultura escolar, que desconsidera todo o contexto em que a escola e seus professores constroem sua ação pedagógica" (p. 158). Os dois estudantes acompanhados ao longo do curso oferecem uma perspectiva um pouco mais animadora, ao confirmarem que o esforço nas disciplinas os ajudou a propor no estágio uma intervenção fundada em reflexões e análises que a tornaram mais próxima da realidade da escola. Não se encontram, entretanto, no texto, registros de ações concretas nessa direção. As escolas continuam a ser vistas como distantes da universidade, que "deveria" procurar maior aproximação com elas, que, por sua vez, "poderiam" se mostrar mais abertas e engajadas na tarefa de formação de futuros professores, o que "também" toca a elas. Essas e outras afirmações semelhantes deixam perceber um cenário ainda marcado pela falta de familiaridade com a realidade de nossas escolas e seus professores, com o próprio estágio, ao qual é atribuída a principal parte da prática introduzida pela PCC. Embora modestas, há, por certo, possibilidades que poderiam ser exploradas por uma mais ativa relação entre universidade e escolas com a entrada da "nova" disciplina. As novas 400 horas por ela introduzidas, ao que parece, não foram ainda aproveitadas pelo lado mais fraco, o estágio. Os desafios, que não são novos, mas há muito conhecidos, acabam atraindo mais atenção do que as possibilidades trazidas pela já não tão "nova disciplina"...

No capítulo 8, Barbosa e Cassiani procuram mostrar como a PCC tem sido vista por professores de cursos de licenciatura da área, por meio de sentidos atribuídos por oito professores já familiarizados com o trabalho em uma universidade federal, UF de Campo Grande. Os depoimentos analisados com base nas obras de Pecheux e de Orlandi indicaram um entendimento da prática próximo ao que se passa nos laboratórios e em outros trabalhos práticos próprios da área da biologia, em suas sub divisões, a serviço da aprendizagem de seus conteúdos. Para que as atividades ligadas à PCC aconteçam, de fato, nas disciplinas específicas, segundo os autores, é preciso que os professores que não são do departamento de educação "pensem o conteúdo e a forma como dimensões intrínsecas e não separadas" (p. 185). Para isso, insistem os autores, é preciso que esses professores estejam preparados em sua formação, o que na legislação não é considerado para o lançamento de suas propostas, como a da própria PCC. Há "uma lacuna entre o currículo oficial e o contexto da prática" (p. 187), que precisa de condições para a sua operacionalização no sentido esperado pela PCC. Isso deveria ser buscado por meio de discussões entre professores e estudantes nas salas de aula. As possibilidades de encontrar essas condições 
devem ser exploradas, não como se fossem funcionar como receitas, mas com base no comprometimento, na autoavaliação e na autocrítica (p. 187). São apontadas como sugestões dentro dessa perspectiva cinco alternativas para um trabalho conjunto, envolvendo professores e alunos no desenvolvimento da PCC no curso de licenciatura. Infelizmente, nenhuma delas inclui um trabalho efetivo junto às escolas... (p. 188). As sugestões levantadas e discutidas nas aulas durante o curso poderiam ser experimentadas nas escolas que recebem os estagiários, em conjunto com os professores supervisores, co-formadores, acompanhando os estudantes em uma concepção de estágio bem mais ativo do que a corrente. Seria a oportunidade de tratar a prática de acordo com o sentido a ela atribuído pelos que vivem no contexto real de nossas escolas.

As autoras do capítulo 9, Pereira e Mohr, são as mesmas do capítulo 1, no qual introduzem a PCC como nova disciplina no currículo dos cursos de licenciatura no início do milênio. Neste capítulo partem do estudo feito para a dissertação de uma das autoras, Pereira, de 2016, e focalizam a perspectiva de professores com experiência de trabalho com esses cursos na UFSC, na área de ciências biológicas. Um questionário dirigido aos 30 professores encarregados das 41 disciplinas que se beneficiam das 400 horas introduzidas pela PCC, oferece às autoras um conjunto de informações, a partir das quais escolheram quatro professores que lhes permitiriam, por entrevistas, compor uma visão sobre a perspectiva do grupo de professores, em suas várias caracterizações. Depoimentos dos quatro professores confirmaram aspectos já constatados em outros estudos sobre o trabalho com a prática focado especialmente pela PCC, concentrado no desenvolvimento de instrumentos e estratégias voltados para o ensino dos conteúdos da área específica, pelos licenciandos e seus professores, ao longo do curso na universidade. Extratos muito interessantes apresentados no texto refletem a preocupação desses professores com sua falta de preparação para o magistério: "eu não estudei para estar em sala de aula, minha formação é toda em pesquisa. Todos nós somos pesquisadores, de ponta, muitos... Então o ensino é um laboratório, entendeu?" (p. 204). Afirmações como essas levam esses professores a reclamar ajuda para enfrentar sua assumida falta de preparo, mas também a afirmar insatisfação com os cursos oferecidos pela universidade ao entrarem para o trabalho nos cursos de licenciatura. Por outro lado, mantêm em suspenso questões há muito reclamando atenção, como a marcada pela lapidar frase de L. Stenhouse, em 1975: "cada professor é um pesquisador em sua sala de aula" (1975). Uma investigação como esta, em área científica, com intenso uso de laboratórios, descortina um cenário propício para aprofundar uma intrigante questão sobre a construção de conhecimento pelos estudantes dentro dos laboratórios. Ao acompanhar esse processo, os professores da área específica poderão aprender lições sobre ensinamentos da prática, sobre como fazer os alunos aprender, o que poderá ser útil na preparação de todos os professores - um aspecto que poderia ser beneficiado por este e por outros estudos reunidos neste livro. Bem como um outro, ligado à concepção de prática dentro da PCC, cujas 400 horas ficaram, em geral, 
confinadas aos limites das IES, deixando a descoberto componente imprescindível ao trabalho nas escolas na formação de futuros professores.

Em mais de 30 páginas, no capítulo 10, três autores, Torres, Silvério e Maestrelli, apresentam um diagnóstico sobre a implementação da PCC em cursos de licenciatura em ciências biológicas na UFSC. O estudo relatado teve por base estudos anteriores dos próprios autores, Torres, em seu estágio de pós-doutorado na UFSC em 2011 e 2012, e Silvério em seu doutorado sob a orientação de Maestrelli, também na UFSC, em 2014, tendo Silvério autor de outro capítulo deste livro ( $\left.\mathrm{n}^{\circ} 7\right)$. A ampla pesquisa partiu da análise dos planos para as disciplinas que receberam horas previstas para a prática pela $\mathrm{PCC}$, prosseguindo para o acompanhamento de algumas pelos pesquisadores com observações e análises. Os estudantes tiveram importante participação na pesquisa, discutindo e opinando com os professores sobre as atividades propostas para a disciplina, tendo sido consultados por meio de um questionário dirigido a 100 licenciandos, sendo entrevistados um número não registrado no texto. As informações convergem para um conjunto variado de atividades planejadas e executadas nas salas de aulas, pelos professores e seus estudantes, tendo em mira a adaptação do conhecimento a ser transmitido a alunos das escolas de educação básica. Essas atividades envolvem a confecção de materiais como jogos ou brinquedos, textos criticados, adaptados ou mesmo elaborados, bem como filmes, vídeos, com os quais os estudantes deveriam trabalhar com os colegas de turma, visando o futuro trabalho com os alunos da "realidade escolar". A relação com essa realidade foi uma das questões levantadas pelos licenciandos, ao comentar o tipo de avaliação das atividades e seus resultados, sempre reduzidos ao âmbito da universidade - o que se reflete em uma de suas expressões no texto sobre "a distância entre o desejável e o que pode ser feito nas escolas públicas e privadas" (p. 235) e a necessidade de aproximação da universidade com a realidade das escolas, por meio de pesquisas e projetos entre as duas. Também o acompanhamento das disciplinas levou os pesquisadores a constatar "que seus trabalhos estão longe da realidade escolar" (p, 232). A falta de atenção aos processos e a concentração nos produtos dessas atividades tão variadas, sem a preocupação de leva-los à discussão com os professores das escolas, o que poderia ser muito enriquecedor, foi também lastimada pelos pesquisadores. Eles concluem insistindo sobre a necessidade de melhorar a preparação os professores da universidade para o trabalho com a PCC, que está deixando de atentar para um aproveitamento bem mais efetivo das novas horas na relação ainda muito frágil com as escolas.

O capítulo 11, de Viana e Coutinho, fechando o livro, talvez devesse ser lido logo em seu início, pois trabalha com interpretações e percepções da PCC ao chegar a cursos de licenciatura em ciências biológicas. Os autores são estudiosos do tema, com trabalhos publicados a partir de um estudo em andamento. Com base em contribuições de autores menos conhecidos, como Sorensen e do nosso bem conhecido Bruno Latour, propõem conceitos muito interessantes, como o de "actantes", indicando fatores ou coisas 
que têm ação, ou agem, nem todos podendo ser chamados de atores, como são designados os humanos. Esse conceito, ao lado do de performance, leva os autores a desvelar múltiplas possibilidades introduzidas pela PCC nas propostas curriculares. Acompanhando o actante e sua performance no PPP (Plano Político Pedagógico) de um curso, eles percebem a PCC atuando como um organizador e estruturador do seu currículo. A distribuição da carga horária e especialmente a análise do ementário das disciplinas, permitem perceber como age a PCC nas propostas curriculares. Uma lista de verbos, no gerúndio, indica o modo como age a PCC, tais como, analisando, discutindo, compreendendo, estimulando, promovendo, entre outros (p. 253), em nove campos disciplinares. Os autores destacam como tipos de performance preponderantes os relacionados à instrumentalização, à análise e à discussão, localizando pontos curiosos ligados a eles em várias disciplinas. Mesmo limitado ao âmbito documental, o trabalho e suas análises oferecem constatações que merecem o registro pelos autores. Entre outras, a de que ao seguir a PCC no PPP do curso observaram que "ela provoca uma necessidade de adequação de disciplinas acadêmicas e da relação entre a universidade e a escola". (p.258). Ao finalizar, afirmam que "uma análise mais profunda sobre os processos de elaboração de um PPP ainda está por ser realizada para buscar respostas para (suas) perguntas". (p. 259).

O conjunto de estudos e pesquisas reunidos neste livro constitui importante contribuição para estudiosos do campo da formação de professores, especialmente interessados em despertar a PCC, "bela adormecida" há quase 20 anos... O cuidado com o qual foram tratados aspectos da cena onde ela repousa assegura o caminho já trilhado e estimula a busca de outros, talvez promissores. De minha parte destaco, dentre eles, o que leva em direção à intensa interação com a escola da educação básica e seus professores, muitas vezes mencionado por vários autores, mas, nunca parecendo efetivamente trilhado, pelo relato das experiências estudadas. O contato com as escolas aparece associado ao estágio, sem a devida consideração das condições necessárias para sua realização satisfatória, sendo uma delas a duração insuficiente, que poderia talvez se beneficiar de horas trazidas pela PCC.

Há também uma ideia subterrânea, por todos os textos, não chegando, contudo, a aflorar à superfície. Ao trabalhar num território específico do campo científico, os autores, em sua maioria, assinalaram a falta de preparação adequada dos professores da área no domínio da pedagogia, deixando de atentar para a possibilidade de discutir com esses colegas ou até de acompanhar algumas das experiências relatadas nos processos de aprendizagem que ocorrem nos laboratórios que possam trazer lições preciosas ao trabalho docente, em sala de aula ou em qualquer outro ambiente.

Recebido em: 18/08/2020 e Aprovado em: 02/12/2020 


\section{Referências:}

STENHOUSE, L. (1975) An introduction to curriculum research and development. Londres: Heinemann.

\section{Sobre a autora:}

\section{MENGA LÜDKE}

Titular Emérita da Pontifícia Universidade Católica do Rio de Janeiro. Doutorada em Sociologia, Universidade de Paris X. Pós-Doutorado na Universidade da Califórnia, Berkeley e Visiting professor no Instituto de Educação da Universidade de Londres. Área de pesquisa e produção bibliográfica, Formação de Professores. E-mail: <menga@puc-rio.br>. 